\title{
High-resolution field measurements of wind-driven rain on an array of low- rise cubic buildings
}

\author{
A. Kubilay ${ }^{\mathrm{a}, \mathrm{b}, *}$, D. Derome ${ }^{\mathrm{a}, \mathrm{b}}$, B. Blocken ${ }^{\mathrm{c}}$, J. Carmeliet ${ }^{\mathrm{a}, \mathrm{b}}$ \\ ${ }^{a}$ Chair of Building Physics, Swiss Federal Institute of Technology ETHZ, Zurich, Switzerland \\ ${ }^{b}$ Laboratory for Building Science and Technology, Swiss Federal Laboratories for Materials Science and \\ Technology EMPA, Dübendorf, Switzerland \\ ${ }^{c}$ Building Physics and Services, Eindhoven University of Technology, Eindhoven, The Netherlands \\ * Corresponding author: Aytaç Kubilay, Institute of Technology in Architecture, Chair of Building \\ Physics, ETH Zurich, Wolfgang-Pauli-Strasse 15, CH-8093, Zurich, Switzerland. Tel.: +41 58765 4276; \\ E-mail address:kubilay@arch.ethz.ch
}

\begin{abstract}
Wind-driven rain (WDR) is one of the most important moisture sources with potential negative effects on the hygrothermal performance and durability of building facades. The impact of WDR on building envelopes can be understood in a better way when the WDR intensity distribution can be accurately predicted. Most field experiments of WDR reported in the literature focused on either stand-alone buildings or on buildings in geometrically complex environments. There is a need for high-resolution measurements in more generic and idealized multi-building configurations. The present study reports WDR measurements that were conducted with high spatial and temporal resolution in a test setup consisting of an array of 9 low-rise cubic building models, located in Dübendorf, Switzerland. Detailed descriptions are provided of the building models, the surroundings, the measuring instruments, the measurements of WDR, wind speed, wind direction, horizontal rainfall intensity and air temperature during three selected rain events, as well as error estimates for the WDR measurements. The datasets of rain events and WDR measurement results are made available online to download and are intended for WDR model development and validation.
\end{abstract}

Keywords: Wind-driven rain, Measurement data, Rainfall, Precipitation, Air flow, Buildings

\section{Introduction}

Wind-driven rain (WDR) is rain with a horizontal velocity component due to its co-occurrence with wind. WDR is one of the most important moisture sources that influence the hygrothermal performance and the durability of building facades. It can lead to several undesired phenomena in building physics, such as surface soiling due to runoff, weathering, algae formation, salt damage and frost damage at exterior wall surfaces, and can be a source of moisture leading to mold growth at inside wall surfaces $[1,2]$. Information on WDR intensities is used as a main boundary condition in building envelope heat-airmoisture (BE-HAM) transport models, reinforcing the need for accurate information on the spatial and temporal distribution of WDR.

Different methods can be used to assess WDR intensities. Several studies have provided driving rain indices, which are an indication of the severity of exposure to WDR calculated from hourly, daily or monthly reference wind speed and reference rainfall intensity [3-6]. In some cases, these indices have been presented as driving rain maps [7-11]. Driving rain indices and driving rain maps can be useful to compare the severity of exposure to WDR at different geographical locations but they do not provide detailed spatial and temporal information on the WDR intensity impinging on building facades. The impinging WDR intensity is governed by a wide range of parameters, such as building geometry, 
environment topography, position on the building facade, wind speed, wind direction, rainfall intensity and raindrop-size distribution [12]. Methods to accurately assess the WDR intensity on building facades should therefore take into account these influencing parameters. In addition to driving rain indices, semiempirical models have been established [13-18]. These models can provide information on the temporal variation of WDR but they often assume the moisture source due to WDR to be uniform across large parts of the facade. This can lead to large errors in simulations of moisture transport in the building envelope, as in reality, WDR intensity is far from uniform across the facade.

Computational Fluid Dynamics (CFD) simulations can be a valuable tool to estimate distribution of WDR intensities across facades [12, 19-24]. However, development and validation of such numerical models require complete WDR measurement datasets, which follow strict guidelines in order to ensure their accuracy and reliability and to keep measurement errors small. Blocken and Carmeliet [14] state that an adequate experimental WDR dataset should comprise and/or be accompanied by the following information: (1) detailed descriptions of the building site, (2) the building geometry and (3) the measurement setup; (4) measurements of the reference wind speed, the reference wind direction and the horizontal rainfall intensity (i.e. the rainfall intensity through a horizontal plane) that have been conducted near the building site and in 'free-field' conditions (i.e. at a position that is not significantly influenced by the presence of the building); (5) WDR measurements at the facades with a sufficiently high resolution in space and time and (6) error estimates for the WDR measurements.

To the knowledge of the authors, up to now, field experiments of WDR focused on either stand-alone buildings or on a particular building in a geometrically complex environment. Lacy [25] showed that the WDR distribution varies considerably with the size of the building and shows a large variation across the building facade. Brown [26] conducted a WDR measurement study on a large number of buildings in Dorset, England. van Mook [27] presented WDR measurements on the main building of Eindhoven University of Technology in the Netherlands. This is a wide high-rise building surrounded by several other similar size buildings in a complex urban environment. Tang et al. [28] presented WDR measurements on the Cathedral of Learning on the University of Pittsburgh campus. This is a rather complex high-rise building that is surrounded by several lower buildings. Blocken and Carmeliet [14] performed WDR measurements on the south-west facade of the VLIET test building in Leuven, Belgium, which is a stand-alone low-rise building composed of three sections: sloped-roof section, flat-roof section with roof overhang and flat-roof section without roof overhang. Nore et al. [29] presented WDR measurements on a low-rise test building located near two other similar size buildings in Trondheim, Norway. Ge and Krpan [30] presented measurements on a wide low-rise building with roof overhang in British Columbia. Finally, Briggen et al. [21] performed WDR measurements on the tower of a historical building, St. Hubertus Hunting Lodge, located in the Netherlands.

For detailed model validation, there is a need for high-resolution measurements in more generic and idealized multi-building configurations. Therefore, the present study reports a WDR measurement dataset with high spatial and temporal resolution for a setup consisting of a regular array of 9 low-rise cubic building models of $2 \mathrm{~m}$ height each. The building models are manufactured so that the measurement setup is adjustable and can be rearranged at a later stage to represent different urban configurations. In multibuilding environments, the wind flow is influenced by other buildings or objects in the vicinity, which will have an impact on the WDR intensities. In an urban environment with an array of low-rise cubic buildings, there are regions where the flow between the buildings is weakly coupled with the free stream flow. These are the recirculation regions where the wind speed values are low. In past research, it has been shown that the effect of turbulent dispersion of raindrops becomes important for cases where smaller droplets travel parallel to the building facade at low wind speed values [2]. Furthermore, Blocken et al. [31] showed that, by upstream and downstream disturbances, buildings have mutual influence on their WDR exposure. The present study involves a relatively high number of WDR gauges with high WDR acquisition resolution that aims to measure and compare spatial distribution of WDR intensity on the facades of different buildings in an urban multi-building configuration. 
In the present paper, section 2 presents the buildings, the surrounding site, the measuring equipment and the error analysis. Section 3 presents the measurement data of three carefully selected rain events. Section 4 estimates the WDR intensities by semi-empirical models and compares the results with the experimental data. Section 5 provides a discussion on the experimental WDR results. Finally, section 6 provides the conclusions.

\section{Measurement setup}

\subsection{Buildings and surrounding site}

The measurement setup is located on the campus of the Swiss Federal Laboratories for Materials Science and Technology (Empa) in Dübendorf in a suburban area located east of the city of Zurich, Switzerland, latitude $47^{\circ} 24^{\prime} 9^{\prime \prime}$ and longitude $8^{\circ} 36^{\prime} 50^{\prime \prime}$. The field measurements aim to study the WDR intensities for a regular array of 9 identical low-rise cubic building models, as shown in Fig. 1(a). The models have dimensions $\mathrm{H} \times \mathrm{H} \times \mathrm{H}=2 \times 2 \times 2 \mathrm{~m}^{3}$ and they are spaced $\mathrm{H}=2 \mathrm{~m}$ apart from each other. The cubes are made of wood panels on a wood structure and finished with protective paint. The roofs are flat and covered with a water resistant polymeric membrane as roofing. The cubes are placed on an asphalt parking lot, and positioned on pavement blocks and wooden bars for further protection and convenience of relocation. The wooden bars have been placed so that they prevent airflow under the cubes for wind from west. The total roof height including the support beneath the cubes is $2.17 \mathrm{~m}$.

In Fig. 1(a), the southwest top corners of the cubes are indicated with dots. Preliminary analysis of the local meteorological data indicates that the main wind direction, from where the most WDR is obtained, is west. The measurements are conducted on the west facades of cubes A and B, indicated in grey in Fig. 1(a). Fig. 1(b) shows a view of the setup from northwest and Fig. 1(c) shows a plan view of the measurement site. The measurement site has an open field with short grass at the south-west of the setup. In west direction, the field is about $35 \mathrm{H}$ long and, further upstream, high trees and buildings are present. In south direction, the field is about $65 \mathrm{H}$ long and, further upstream, high-rise buildings and a motorway are present. From northwest to east, there are several nearby low-rise and high-rise buildings. The closest of them are located at about $10 \mathrm{H}$ distance from the experimental setup to northwest and northeast.

\subsection{Measurement equipment}

The wind speed, the wind direction, the wind elevation, the air temperature and the horizontal rainfall intensity are recorded in addition to the WDR in order to provide the required data to allow analysis of the WDR process and to provide representative validation data for possible numerical simulations. Wind direction is the azimuth angle from north. Wind elevation is the angle of the wind velocity vector with the horizontal plane.

\subsubsection{Wind measurements}

In order to measure the approach-flow wind direction and wind speed, a meteorological mast is positioned west of the measurement site (see Fig. 1(c)). The measurement site is located within an internal boundary layer where the approach flow profile is still developing. Thus, the position of the mast has to be chosen as close as possible to the setup to catch the most representative approach-flow boundary layer profile.

However, at the same time, its location should be outside the region influenced by the cubes themselves in order to measure the unobstructed free-field wind profile. The position of the mast is chosen to be at $3 \mathrm{H}=$ $6 \mathrm{~m}$ away from the array of cubes, as determined by preliminary CFD simulations. Note that, for other wind directions such as southeast, east and northeast, the cubes influence the wind-flow pattern at the meteorological mast; therefore, for these wind directions, the actual approach flow profile will not be obtained. 
The meteorological mast is equipped with a 3D ultrasonic anemometer at $8.4 \mathrm{~m}$ height, which provides information on wind speed, wind direction and wind elevation. Additionally, two cup anemometers are installed at 2.4 and $5.4 \mathrm{~m}$ heights to measure the approach wind flow profile. The sampling rate for the anemometers is $1 \mathrm{~Hz}$. Fig. 2 shows the measured wind profiles for the wind flow perpendicular to the test facades (from west) and for $45^{\circ}$ oblique directions (from northwest and southwest). The markers show the measured values, whereas the lines show the fitted curve using the neutrally stratified atmospheric boundary layer profile:

$$
U(y)=\frac{u^{*}{ }_{A B L}}{\kappa} \ln \left(\frac{y+y_{0}}{y_{0}}\right)
$$

where $U(y)$ denotes the mean streamwise wind speed at a height $y$ above the ground plane, $u^{*}{ }_{A B L}$ the atmospheric boundary layer (ABL) friction velocity, $\kappa$ the von Karman constant ( 0.42 in the present study) and $y_{0}$ the aerodynamic roughness length. For wind from west and southwest, $u^{*}{ }_{A B L} / U=0.24$ and $y_{0}=0.49$ $\mathrm{m}$. For wind from northwest, $u^{*}{ }_{A B L} / U=0.34$ and $y_{0}=1.02 \mathrm{~m}$. Note that, as the approach flow is in reality in an internal boundary layer, the log-law assumption is a simplification. The location of the measurement site and related surface roughness characteristics by the Davenport-Wieringa roughness classification [32] are shown in Fig. 3. According to this classification, the surface roughness needs about $10 \mathrm{~km}$ of upstream length to adapt. The measured wind profile from northwest indeed has the characteristics predicted by the Davenport-Wieringa specifications. West and southwest profiles have, on the other hand, a lower roughness than one would expect. Additionally, two additional ultrasonic anemometers were installed on cube A (Fig. 4), in order to obtain detailed information on the wind flow around the cubes and to provide additional validation data for wind flow calculations by CFD.

Fig. 5 shows the 10-min averaged wind speed data from the anemometers on the meteorological mast for a duration of one week. Note that the cup anemometers have a threshold sensitivity of $0.2 \mathrm{~m} / \mathrm{s}$ and thus, the lines are constant at that value for lower wind speeds. From the measured data, the diurnal cycle of wind speed values is clear, with values lower during night time compared to day time.

Fig. 6 shows the wind rose based on 10-min averaged data recorded at $2.4 \mathrm{~m}$ height during rain events between May - October, 2013. Both the highest wind direction frequency and the highest wind speed during rain events occur for wind from northwest to southwest. Note also that the wind speed values are lower for northwest compared to west and southwest, probably due to the nearby buildings in that direction.

\subsubsection{Rain measurements}

The horizontal rainfall intensity is measured $0.4 \mathrm{~m}$ above the ground by a rain gauge positioned near the weather mast. The rain gauge has a horizontal orifice and a tipping bucket mechanism. The sampling rate for the rain gauge is $1 \mathrm{~Hz}$. The effective volume of the tipping bucket is $2.15 \mathrm{ml}$ and the rain gauge orifice is $0.02 \mathrm{~m}^{2}$, which results in a resolution of about $0.11 \mathrm{~mm} /$ tip. Note that for rainfall intensities lower than $0.65 \mathrm{~mm} / \mathrm{h}$, the tipping bucket data will not be accurate, as 10-min rainfall amounts, on average, will be smaller than the rain gauge resolution. As a result, the bucket may not tip during a 10-min period even though the rain event goes on, but tip during a later 10-min period.

\subsubsection{WDR measurements}

WDR gauges are not manufactured industrially and there exists no standard on their design $[1,14,33]$. The studies by Hendry [34] and Lacy [25] presented early comparative studies between different WDR gauges. Högberg et al. [35] reported differences up to $100 \%$ in measured WDR amount by different 
gauges. Kragh [36] developed a WDR gauge, which is suspended from a load cell and stainless steel collector. van Mook [27, 37] designed a WDR gauge with a PTFE (polytetrafluoroethylene) coated collector with a wiper and a balance. Högberg [38] designed a WDR gauge with special collector to limit splashing losses. Blocken and Carmeliet [14] used WDR gauges with PMMA (polymethyl-methacrylate) collection surfaces and reservoirs equipped with pressure sensors.

The WDR gauge collectors in the present study were manufactured at Empa following the guidelines of Blocken and Carmeliet [33]. As shown in Fig. 7, they were made of aluminum with catch surfaces of ordinary glass sheets to promote runoff [33]. The collector area is $0.2 \times 0.2 \mathrm{~m}^{2}$. The collectors are connected via tubing to the tipping bucket mechanisms, which are placed inside the building models. This way, frost problems for the buckets are avoided and the evaporation from the bucket is less variable during the rain event. The tipping buckets each have an effective tipping bucket volume of about $1 \mathrm{ml}$. The collector area and effective bucket volume lead to a resolution that is about 4 times higher than the horizontal rain gauge, or about $0.025 \mathrm{~mm} / \mathrm{tip}$. Sampling rate for the WDR gauges is $1 \mathrm{~Hz}$. There are 18 WDR gauges in total, 9 on cube A and 9 on cube B. Table 1 and Table 2 show the tipping bucket resolutions for each WDR gauge on cubes $\mathrm{A}$ and $\mathrm{B}$, respectively. The tipping bucket resolutions are dependent on the effective bucket volumes, which can be modified by lowering or raising calibration screws under the bucket. Since it is a mechanical system, the effective bucket volumes are not exactly the same for each gauge. The rain gauge and the WDR gauges were calibrated in February 2013, prior to the start of the measurements.

Fig. 4 shows the positions of the WDR gauges on the test facade of cube A. The placement on the test facade of cube B is identical. The lowest collector is located at about $0.5 \mathrm{~m}$ height from the ground. A lower position was not possible because the tubing, which leads to the tipping bucket, was aimed to be minimum at a $45^{\circ}$ angle for effective drainage.

\subsection{Measurement accuracy}

The measurements were conducted capitalizing from the knowledge gained in previous experiments on small and large buildings [1, 12, 14, 21,39]. The study by Blocken and Carmeliet [33] indicates the following possible error sources that should be taken into account when measuring WDR on building facades: (1) evaporation of droplets adhered to the collection area of the WDR gauge, (2) error due to the rest-water that remains in the tipping bucket, (3) splashing of drops from the collection area, (4) condensation on the collection area, and (5) wind errors due to the disturbances of the wind field and the raindrop trajectories near the WDR gauge by the presence of the gauge itself.

In Blocken and Carmeliet $[14,33]$, the most important cause of measurement errors is stated to be evaporation of adhesion water on the gauge collection area and this was confirmed in Nore et al. [29], where evaporation of adhesion water, $E_{A W}$, and the rest-water error, $E_{R W}$, in the tipping bucket were found to be the largest error sources. During and after a rain event, there is always a certain amount of water adhered to the collection area, which is not measured by the gauge. A numerical study by Blocken and Carmeliet [33] shows that all the impinged droplets adhere to the surface until a certain threshold of impinged amount of WDR is reached. After the threshold value, the total volume of adhered droplets remains constant, thus the error is considered to be important especially for light to moderate rainfall intensities. The adhered amount of rain on the collector and the tube is found to be $0.128 \mathrm{~mm}$ by spraying tests. In order to keep the measurement errors due to evaporation of adhered droplets as small as possible, rain events with large amounts of WDR must be selected. This ensures that the loss of water due to evaporation of the adhered droplets is kept at a relatively limited amount. Furthermore, rain events with less dry periods in between the rain showers are expected to limit the errors due to evaporation of adhered droplets, as well as the rest-water error. Using a tipping bucket with a smaller bucket volume will also decrease the rest-water error by increasing the measurement resolution. 
The error due to splashing and the wind error are not as easy to estimate. Hence, the selection of the rain events should ensure that the related errors are small. The influence of the splash-error is expected to be high only for rain events with larger raindrop sizes and high wind speed values. It is argued that the selected rain events should have reference wind speed values (at $y=10 \mathrm{~m}$ ) lower than $10 \mathrm{~m} / \mathrm{s}$ and horizontal rainfall intensities lower than $20 \mathrm{~mm} / \mathrm{h}$ in order to keep splashing error small [33]. Blocken and Carmeliet [33] and Nore et al. [29] argue that the error associated with condensation on the collector surface is quite limited during rain events due to limited radiation losses to the sky. Finally, for a small wind error, the protrusion of the WDR gauge out of the plane of the facade should be small, the wind speed values should not be high and the wind direction during the rain event must be approximately perpendicular to the building facade.

The time interval for which the experimental data are provided is chosen to be 10 minutes following the guidelines by van der Hoven [40], Sumner [41] and Blocken and Carmeliet [42, 43] in order to minimize the errors related to the time resolution of meteorological datasets. The measured wind speed, wind direction and wind elevation during rain events in the dataset will be presented in terms of 10-min averaged values. Similarly, the horizontal rainfall amount and the WDR amount are in terms of 10-min summed values.

\section{Measurement results}

\subsection{Overview of registered rain events}

Fig. 8 provides an overview of 29 measured rain events between May 2013 and October 2013. Rain events with rainfall amount lower than $2.0 \mathrm{~mm}$ are excluded in Fig. 8. An important aspect is the proper identification of a single rain event. In the literature, there is a wide range of criteria in defining the start and end of rain events [44]. The minimum gap between two different rain events is largely chosen based on the application. Use of short inter-event gaps can lead the rain event to be too short to obtain meaningful WDR data. Use of long inter-event gaps can lead to large changes in wind direction during the rain event. In the present study, a rain event is assumed to end if the following dry period takes longer than $12 \mathrm{~h}$. In Fig. 8, each circle corresponds to a single rain event. It represents the effective rainfall intensity, effective wind direction and effective wind speed during rain events. The sizes of the circles are proportional to the rainfall amount during each rain event. Blocken et al. [45] and Nore et al. [29] argue that effective wind direction is a better representative variable than arithmetically averaged wind direction, as it is weighted by the 10-min averaged wind speed $U$, and the 10-min summed rainfall intensity $R_{h}$. In the present study, the effective wind direction is calculated by breaking up wind velocity into normal and tangential components and weighting them by the rainfall intensity values. This way, the error due to wind direction fluctuations between opposite directions is prevented. The effective wind direction, $\varphi_{\text {eff }}$, the effective wind speed at $2.4 \mathrm{~m}$ height, $U_{\text {eff, }}$ and the effective rainfall intensity, $R_{h, e f f}$, for a rain event are calculated using Eqs. 2-4, respectively. $U_{\mathrm{t}}$ denotes the tangential velocity, $U_{\mathrm{t}, \text { eff }}$ the tangential effective velocity, $U_{\mathrm{n}}$ the normal velocity, $U_{\mathrm{n}, \text { eff }}$ the normal effective velocity, each at $2.4 \mathrm{~m}$ height.

$$
\begin{aligned}
& \varphi_{\text {eff }}=\tan ^{-1}\left(\frac{U_{\mathrm{t}, e f f}}{U_{\mathrm{n}, e f f}}\right), \quad U_{\mathrm{t}, \text { eff }}=\frac{\sum R_{h} U_{\mathrm{t}}}{\sum R_{h}}, \quad U_{\mathrm{n}, \text { eff }}=\frac{\sum R_{h} U_{\mathrm{n}}}{\sum R_{h}} \\
& U_{\text {eff }}=\sqrt{\left(U_{\mathrm{t}, \text { eff }}\right)^{2}+\left(U_{\mathrm{n}, e f f}\right)^{2}}
\end{aligned}
$$


$R_{h, e f f}=\frac{\sum R_{h}}{n}$

where $n$ is the number of time steps during which $R_{h}>0$. In Fig. 8 , the most frequent effective wind directions during rain events seem to be between northwest and southwest. Moreover, there seems to be a concentration of the effective rainfall intensity at a value of about $2 \mathrm{~mm} / \mathrm{h}$. The effective wind speed varies between $0-1.5 \mathrm{~m} / \mathrm{s}$.

The catch ratio for a rain event is defined as the ratio of WDR amount, $S_{w d r}$, and the horizontal rainfall amount through the horizontal plane, $S_{h}$ :

$$
\eta=\frac{S_{w d r}}{S_{h}}
$$

\subsection{Results for selected rain events}

Note that the data in Fig. 8 also include the rain events which do not comply with all the guidelines mentioned in section 2.3. As the given guidelines must be strictly followed in order to keep the measurement errors small, only a few rain events are suitable for validation studies. In this section, three rain events are discussed in detail. The rain events are selected based on the guidelines in section 2.3 and each have different characteristics. The dataset contains seven rain events, including the three in this paper, with relative error $E_{T O T}=\left(E_{A W}+E_{R W}\right) / S_{w d r}<50 \%$ for all WDR gauges. The dataset is available at the following website:

\section{http://www.carmeliet.arch.ethz.ch/ResearchDatabase/Wind-drivenRain}

Each rain event in the following subsections is summarized with three graphs showing the meteorological data, measured by the meteorological mast and the rain gauge, and the cumulative WDR amount, measured by each WDR gauge, and with two figures that show the catch ratio for each WDR gauge on cubes $\mathrm{A}$ and $\mathrm{B}$.

\subsubsection{Rain event 1: May 30 - June 1, 2013}

The meteorological data for the rain event on May $30-$ June 1, 2013 are shown in Fig. 9(a). $\varphi_{e f f}=268^{\circ}$, $U_{\text {eff }}=0.8 \mathrm{~m} / \mathrm{s}$ at $2.4 \mathrm{~m}$ height and $U_{\text {eff }}=1.2 \mathrm{~m} / \mathrm{s}$ at $5.4 \mathrm{~m}$ height, $R_{h, \text { eff }}=2.2 \mathrm{~mm} / \mathrm{h}$ and $S_{h}=72 \mathrm{~mm}$. The mean air temperature is $11.4{ }^{\circ} \mathrm{C}$. The total duration of the rain event is about 50 hours. Between May 31 02:00 and June 1 03:00, rain goes on almost continuously with only very short interruptions. During the day time, the wind direction is mostly west and the wind speed values are higher, up to $2 \mathrm{~m} / \mathrm{s}$, at $2.4 \mathrm{~m}$ height. From the evening through the night, the wind direction changes to north and the wind speed values at $2.4 \mathrm{~m}$ height decrease.

Fig. 9(b) and (c) show the cumulative WDR measured by the gauges during the rain event and the catch ratio values at the end of the rain event on the facades of cubes $A$ and $B$, respectively. On cube $B$, the WDR gauges 4 and 8 had problems in registering the tippings and therefore they were disconnected. On the cumulative WDR intensity graphs, the blue color corresponds to the south side of the facade and red to the north side of the facade. On the catch ratio figures, the positioning of the rain collectors is drawn to scale. The WDR gauges at different heights on the facade are indicated by different markers. Note that, at the beginning of the rain event, as the wind direction is mainly from east, there is only a negligible amount of WDR recorded until 02:00. Even after that, due to low wind speed, the WDR collection is relatively 
slow until about 08:00. Table 3 lists the total measured WDR amount by each gauge, as well as the corresponding error estimates for the rain event.

The error consists of evaporation of adhered water droplets, $E_{A W}$, and the rest-water error, $E_{R W} . E_{A W}$ is estimated to be $0.640 \mathrm{~mm}$, which is calculated by multiplication of the adhered amount of rain with 5 dry periods during the rain event. Similarly, $E_{R W}$ is estimated to be about $0.125 \mathrm{~mm}$ for each WDR gauge, respectively. The number of dry periods is estimated by the number of plateaus in the cumulative WDR graphs rather than the data from the horizontal rain gauge. This way, firstly, the interruptions due to delay in the registration of WDR by the tipping bucket of horizontal rain gauge are not counted as dry periods. Secondly, taking only the horizontal rainfall into account can be misleading for some cases, in which the wind direction is changing for long time periods, where there is no WDR registration. These periods should also be counted as dry periods, as there is some amount of evaporation on the WDR gauge collector. Note that the error estimations are very conservative as it assumes total evaporation of the adhered WDR amount and the rest water before the rain shower starts again. The remaining errors are expected to be lower for this rain event due to low wind speed at the height of the cubes and perpendicular flow direction to the western facades.

\subsubsection{Rain event 2: June 9-10, 2013}

The meteorological data for the rain event on June 9-10, 2013 are shown in Fig. 10(a). $\varphi_{\text {eff }}=249^{\circ}, U_{\text {eff }}=$ $0.9 \mathrm{~m} / \mathrm{s}$ at $2.4 \mathrm{~m}$ height and $U_{\text {eff }}=1.3 \mathrm{~m} / \mathrm{s}$ at $5.4 \mathrm{~m}$ height, $R_{h, \text { eff }}=4.8 \mathrm{~mm} / \mathrm{h}$ and $S_{h}=35 \mathrm{~mm}$. The mean air temperature is $14.3^{\circ} \mathrm{C}$. This rain event has an effective rainfall intensity of more than twice the one of the previous rain event, but the rainfall amount is lower. Hence this rain event is a shorter one with a duration of about 9 hours in total. On the other hand, it is more homogeneous in terms of wind speed and wind direction values. During the first half, the rainfall intensity is relatively high, homogeneous and without interruptions. After that, the rainfall intensity decreases and the rain event is interrupted by short dry periods. The wind speed at $2.4 \mathrm{~m}$ height is mostly between $1-2 \mathrm{~m} / \mathrm{s}$ during the whole rain event. The wind direction is mostly fluctuating between west and southwest, except for the last hour where it switches to east-southeast.

Fig. 10(b) and (c) show the cumulative WDR measured by the gauges during the rain event and the catch ratio values at the end of the rain event on the facades of cubes $\mathrm{A}$ and $\mathrm{B}$, respectively. The WDR distribution on both cubes is very similar to that of the previous rain event. Note that all WDR gauges start recording as soon as the rain event starts and the WDR amount increases quite sharp at the beginning. The WDR collection stops in all gauges once the wind direction switches to east near the end of the rain event. Table 4 lists the total measured WDR amount by each gauge as well as the corresponding error estimates. $E_{A W}$ and $E_{R W}$ estimations correspond to the evaporation of water that adhered on the collector and stayed in the bucket after the rain event, respectively. Note that, even though the rainfall amount is lower than rain event 1 , the relative error is also lower.

\subsubsection{Rain event 3: September 16-19, 2013}

The meteorological data for the rain event on September 16-19, 2013 are shown in Fig. 11(a). $\varphi_{\text {eff }}=246^{\circ}$, $U_{\text {eff }}=1.2 \mathrm{~m} / \mathrm{s}$ at $2.4 \mathrm{~m}$ height and $U_{\text {eff }}=1.6 \mathrm{~m} / \mathrm{s}$ at $5.4 \mathrm{~m}$ height, $R_{h, \text { eff }}=1.8 \mathrm{~mm} / \mathrm{h}$ and $S_{h}=36 \mathrm{~mm}$. The mean air temperature is $12.4{ }^{\circ} \mathrm{C}$. This rain event has about the same rainfall amount as the one on June 0910,2013 , however, with many dry periods. The rain showers consist of high peaks of rainfall intensity for short periods. The total rain event duration is more than 48 hours. The wind direction is mostly between southwest and west except for some short periods when it switches to south-southeast.

Fig. 11(b) and (c) show the cumulative WDR measured by the gauges during the rain event and the catch ratio values at the end of the rain event on the facade for cubes $A$ and $B$, respectively. The higher effective wind speed during this rain event leads to higher catch ratio values than for the previous two rain events. 
Table 5 lists the total measured WDR amount by each gauge, as well as the corresponding error estimates for the rain event. $E_{A W}$ and $E_{R W}$ estimations correspond to 10 dry periods during which the rain event is interrupted. The relative error for this rain event is estimated to be higher than for the previous two due to many dry periods and lower rainfall amount compared to rain event 1 .

\section{WDR calculation by semi-empirical models}

In this section, WDR is calculated on the facades of cubes A and B using semi-empirical models, i.e. models of ISO 15927-3 [46] and ASHRAE [47]. The semi-empirical models have been used in building physics research to provide boundary conditions for heat-air-moisture (HAM) transfer analysis of building components. Comparing these calculations with the corresponding measurements allows an assessment of the accuracy of these semi-empirical models.

\subsection{ISO 15927-3 model}

In the ISO model, the WDR intensity is defined as:

$$
R_{w d r}=\frac{2}{9} C_{R} C_{T} O W U_{10} R_{h}^{0.88} \cos \theta
$$

where $C_{R}$ is the roughness coefficient, $C_{T}$ the topography coefficient, $O$ the obstruction factor, $W$ the wall factor, $U_{10}$ the hourly reference wind speed at $10 \mathrm{~m}$ height and $R_{h}$ the hourly rainfall intensity. $\theta$ is the angle - in the horizontal plane - between the wind direction and the normal to the facade. $C_{R}$ takes into account the change of mean wind speed at the site due to the height above the ground and the upstream roughness of the terrain. It is given by:

$$
\begin{array}{ll}
C_{R}(y)=K_{R} \ln \left(\frac{y}{y_{0}}\right) & \text { for } y \geq y_{\min } \\
C_{R}(y)=C_{R}\left(y_{\min }\right) & \text { for } y<y_{\min }
\end{array}
$$

where $y$ is the height above ground, $K_{R}$ the terrain factor, $y_{0}$ the aerodynamic roughness length and $y_{\min }$ a minimum height.

Although the standard strictly only guides the calculation of the average annual amount of WDR and the amount of WDR in the worst likely spell in a 3-year period, this method could theoretically also be used to determine WDR intensities or amounts for any spell within a year [2].

\subsection{ASHRAE model}

In the ASHRAE model, the WDR intensity is defined as:

$$
R_{w d r}=0.2 F_{E} F_{D} U_{10} R_{h} \cos \theta
$$

where $F_{E}$ denotes the rain exposure factor and $F_{D}$ the rain deposition factor. The other parameters have the same definition as in the ISO model.

\subsection{Results}

Table 6 presents the parameters that are used for both models. Note that the ISO model only includes a few types of buildings. Therefore, the wall factor, $W$, was chosen the same as the average value for a two- 
storey building with a flat roof. The obstruction factor, $O$, for cube $\mathrm{B}$ is chosen to be the minimum value given in the norm, as the actual distance is closer than the minimum distance defined in the norm. Furthermore, the ISO model states that if a change of upstream roughness occurs within $1 \mathrm{~km}$, the smoothest upstream terrain category must be used. Hence, the smoother $y_{0}=0.05 \mathrm{~m}$, representing farm land with trees [46], is chosen.

Fig. 12 shows the catch ratios on the windward facades of cubes A and B estimated for the rain events in section 3.2 by the semi-empirical models and compares them to the measured values averaged over facade. The values estimated by the semi-empirical models show very large deviations. The ISO model tends to underestimate the average of measured values by about $59 \%$ on cube $\mathrm{A}$ and by about $87 \%$ on cube $\mathrm{B}$. The ASHRAE model overestimates the average of measured values by up to $88 \%$ on cube A and by up to $40 \%$ on cube B. The ASHRAE model estimates the catch ratio on the sheltered cube B by a lower discrepancy of $24 \%$ during the rain events 1 and 2 . However, it is not as accurate for the rain event 3 . Moreover, both models estimate larger differences in WDR intensities between cubes A and B than it is the case for field measurements. The reason behind the difference in catch ratios between cubes $\mathrm{A}$ and $\mathrm{B}$ is the fact that the models only consider the horizontal distance between the cubes to take the sheltering into account. Neither the ISO nor the ASHRAE model takes the full size of the neighboring buildings as a factor. In case a wide high-rise building with high wind-blocking effect would be located behind the cube A, it would decrease the measured catch ratio on cube A, decreasing the discrepancy of the ISO model while increasing the discrepancy of the ASHRAE model. However, the wind-blocking effect from a downstream building is not a factor that is considered by the ISO model [31]. Furthermore, both models lack the information on spatial distribution of WDR intensity on the facade.

The current semi-empirical models give limited information on WDR distribution and they are more convenient for simpler geometries that involve less interaction from surrounding objects. A semiempirical model appropriate for a specific case is one that takes into account all relevant factors. Blocken et al. [16] and de Freitas et al. [17] show that various semi-empirical models can show differences of up to $300 \%$. On the other hand, semi-empirical models provide a fast approach to provide information on WDR to be used as boundary condition in BE-HAM transport models. An alternative is using CFD simulations to obtain detailed WDR deposition patterns on facades [1,2]. To the best of our knowledge, this approach has up to only been used a few times [45, 48, 49]. Even though CFD simulations are mostly computationally expensive, they can be used to obtain a database of catch ratio charts for various reference wind direction, wind speed and rainfall intensity values. This database can be coupled with BEHAM models for various rain conditions on complex geometries. The field experiment dataset in the present paper is intended to support the improvement of both semi-empirical and CFD models of WDR.

\section{Discussion}

For both cubes, the WDR distributions on the west facades show some common patterns. For a rain event with wind direction perpendicular to the facade, the highest catch ratio values are located at the top corners and the top edge of the facade due to the higher wind speed values at that height, as well as the acceleration of air above the building. Similarly, the side edges have higher WDR compared to the central part of the buildings. The WDR intensities on the lower two thirds of the facade of cube B is lower than the one of cube A. The shielding effect on cube B by the upstream cubes is expected to be larger at larger wind speed values. Droplets with different sizes have different responses to wind speed values, therefore it is hard to find a simple relation between the wind speed and the shielding effect. The smallest size droplets in the spectrum can easily follow the vortices in the air flow and still hit the shielded building facade due to their small inertia. For a specific wind speed, medium size droplets can be shielded by the upstream cubes, but larger ones not, due to their more vertical trajectories. The WDR distribution on the facade will change according to a combination of the responses of different droplet sizes. 
Furthermore, note that the catch ratio values are not equal on both sides of the cubes. The catch ratio values on the north side of the facades are lower than the values on the south side of the facades. This conclusion is more evident for the rain event 1 , during which the effective wind direction is perpendicular to the western facade. The reason behind the lateral WDR gradients can be investigated by lateral wind speed difference of the approach flow. This is particularly of interest because of the low and high rise buildings located northwest-north of the measurement site. Fig. 13 compares the wind velocity components values measured by the two ultrasonic anemometers positioned on cube A (see Fig. 4) between September 20th, 2013 and October 28th, 2013 from various wind directions. The mean lateral and vertical wind velocity components are similar for both ultrasonic anemometers. Note that the vertical component is always positive, possibly due to flow directed towards the top of the cube. The mean wind velocity component normal to the western facade is higher for wind directions from southwest to west, as the wind is less obstructed by other buildings and trees. Furthermore, the mean normal component measured by the anemometer on the northern side is higher by about $14.2 \%$ for wind directions between southwest and west.

This study presents field measurements in a generic and idealized multi-building configuration with an array of 9 equally sized cubic building models. The configuration with equal distances between each cube is only one of the many possible model geometries. The measurement setup allows for several other generic geometries that are common in urban areas, e.g. street canyons with aspect ratio of 1:3 or 1:4 with varying heights, single tower building surrounded by low-rise buildings, courtyard geometry. Measurements in different geometries can show how much the WDR on facade is different due to the changes in local airflow features, even though the meteorological conditions are identical.

\section{Conclusions}

This paper presented a new measurement setup, composed of an array of low-rise cubic buildings, for the documentation of wind-driven rain. The measurement setup was designed and installed at the Swiss Federal Laboratories for Materials Science and Technology (Empa) in Dübendorf, Switzerland. This paper provides the description of the measurement geometry, surroundings of the measurement area, measuring equipment, as well as the experimental data of three selected rain events. The dataset of rain events can be downloaded from the given website. The dataset intends to serve as an insight into WDR distribution in an environment where buildings mutually influence their wind-driven exposure, as well as a tool for model development, verification and validation.

\section{Acknowledgements}

The research was supported through the Swiss National Science Foundation (SNF) - Project no. 135510. The technical assistance of Rudi Blessing, Beat Margelisch, Roger Vonbank and David Morice is greatly acknowledged.

\section{References}

[1] Blocken B, Carmeliet J. A review of wind-driven rain research in building science. J Wind Eng Ind Aerodyn. 2004;92:1079-1130.

[2] Blocken B, Carmeliet J. Overview of three state-of-the-art wind-driven rain assessment models and comparison based on model theory. Build Environ. 2010;45:691-703.

[3] Zhu D, Mallidi SR, Fazio P. Quantitative driving rain exposure on a vertical wall at various Canadian cities. Build Environ. 1995;30:533-544.

[4] Giarma C, Aravantinos D. On building components' exposure to driving rain in Greece. J Wind Eng Ind Aerod. 2014;125:133-145.

[5] Rydock JP, Lisø KR, Førland EJ, Nore K, Thue JV. A driving rain exposure index for Norway. Build Environ. 2005;40:1450-1458.

[6] Sauer P. An annual driven rain index for China. Build Environ. 1987;22:239-240.

[7] Boyd DW. Driving-rain map of Canada. DBR/National Research Council, TN 398, Ottawa. 1963. 
[8] Chand I, Bhargava PK. Estimation of driving rain index for India. Build Environ. 2002;37:549-554.

[9] Sahal N. Proposed approach for defining climate regions for Turkey based on annual driving rain index and heating degree-days for building envelope design. Build Environ. 2006;41:520-526.

[10] Pérez-Bella JM, Domínguez-Hernández J, Rodríguez-Soria B, del Coz-Díaz JJ, Cano-Suñén E. Estimation of the exposure of buildings to driving rain in Spain from daily wind and rain data. Build Environ. 2012;57:259-270.

[11] Pérez-Bella JM, Domínguez-Hernández J, Cano-Suñén E, del Coz-Díaz JJ, Alonso-Martínez M. Global analysis of building façade exposure to water penetration in Chile. Build Environ. 2013;70:284-297.

[12] Blocken B, Carmeliet J. Spatial and temporal distribution of driving rain on a low-rise building. Wind Struct. 2002;5:441-462.

[13] Straube JF, Burnett EFP. Simplified prediction of driving rain deposition. Proceedings of International Building Physics Conference, Eindhoven. 2000.

[14] Blocken B, Carmeliet J. High-resolution wind-driven rain measurements on a low-rise building - experimental data for model development and model validation. J Wind Eng Ind Aerodyn. 2005;93:905-928.

[15] Blocken B, Dezsö G, van Beeck J, Carmeliet J. Comparison of calculation models for wind-driven rain deposition on building facades. Atmospheric Environment. 2010;44:1714-1725.

[16] Blocken B, Abuku M, Nore K, Briggen PM, Schellen HL, Thue JV, Roels S, Carmeliet J. Intercomparison of winddriven rain deposition models based on two case studies with full-scale measurements. J Wind Eng Ind Aerodyn. 2011;99:448-459.

[17] de Freitas SS, Barreira E, de Freitas VP. Quantification of wind-driven rain and evaluation of façade humidification. Central European Symposium on Building Physics, September 9-11, Vienna, Austria. 2013.

[18] Coutu S, Wyrsch V, Rossi L, Emery P, Golay F, Carneiro C. Modelling wind-driven rain on buildings in urbanized area using 3-D GIS and LiDAR datasets. Build Environ. 2013;59:528-535.

[19] Kubilay A, Derome D, Blocken B, Carmeliet J. CFD simulation and validation of wind-driven rain on a building facade with an Eulerian multiphase model. Build Environ. 2013;61:69-81.

[20] Huang SH, Li QS. Numerical simulations of wind-driven rain on building envelopes based on Eulerian multiphase model. J Wind Eng Ind Aerodyn. 2010;98:843-857.

[21] Briggen PM, Blocken B, Schellen HL. Wind-driven rain on the facade of a monumental tower: numerical simulation, full-scale validation and sensitivity analysis. Build Environ. 2009;44:1675-1690.

[22] Hangan H. Wind-driven rain studies. A C-FD-E approach. J Wind Eng Ind Aerodyn. 1999;81:323-331.

[23] Lakehal D, Mestayer PG, Edson JB, Anquetin S, Sini JF. Eulero-Lagrangian simulation of raindrop trajectories and impacts within the urban canopy. Atmospheric Environment. 1995;29:3501-3517.

[24] Choi ECC. Simulation of wind-driven-rain around a building. J Wind Eng Ind Aerodyn. 1993;46-47:721-729.

[25] Lacy RE. Driving-rain maps and the onslaught of rain on buildings. RILEM/CIB Symposium on Moisture Problems in Buildings, Helsinki, Finland. 1965.

[26] Brown B. Field measurements to gauge catch ratios of free-space driving rain on house walls at exposed estates in Dorset. Building Research Establishment Note. 1988.

[27] van Mook FJR. Driving rain on building envelopes. Ph.D. thesis, Eindhoven University of Technology, Eindhoven, The Netherlands; 2002.

[28] Tang W, Davidson Cl, Finger S, Vance K. Erosion of limestone building surfaces caused by wind-driven rain: 1. Field measurements. Atmos Environ. 2004;38:5589-5599.

[29] Nore K, Blocken B, Jelle BP, Thue JV, Carmeliet J. A dataset of wind-driven rain measurements on a low-rise test building in Norway. Build Environ. 2007;42:2150-2165.

[30] Ge H, Krpan R. Field measurement of wind-driven rain on a low-rise building in the coastal climate of British Columbia. Proceedings of the 11th Canadian Conference on Building Science and Technology, March, Banff, Alberta. 2007.

[31] Blocken B, Dezso G, van Beeck J, Carmeliet J. The mutual influence of two buildings on their wind-driven rain exposure and comments on the obstruction factor. J Wind Eng Ind Aerodyn. 2009;97:180-196.

[32] Wieringa J. Updating the Davenport roughness classification. J Wind Eng Ind Aerodyn. 1992;41:357-368.

[33] Blocken B, Carmeliet J. On the accuracy of wind-driven rain measurements on buildings. Build Environ.

2006;41:1798-1810.

[34] Hendry IWL. Comparison between two types of wall rain gauge. Building Research Station, Internal note, SL/IN1. 1964.

[35] Högberg A, Kragh M, van Mook FJR. A comparison of driving rain measurements with different gauges. 5th Symposium of Building Physics in the Nordic Countries, Göteborg, Sweden. 1999. p. 361-368.

[36] Kragh MKK. Microclimatic conditions at the external surface of building envelopes. Ph.D. thesis, Department of Buildings and Energy, Technical University of Denmark, Denmark. 1998.

[37] van Mook FJR. Description of the measurement set-up for wind and driving rain at the TUE. Report FAGO 9804K. 1998.

[38] Högberg A. Microclimate load: transformed weather observations for use in design of durable buildings, Ph.D. thesis, Department of Building Physics, Chalmers University of Technology, Göteborg, Sweden. 2002.

[39] Blocken B, Carmeliet J. The influence of the wind-blocking effect by a building on its wind-driven rain exposure. J Wind Eng Ind Aerodyn. 2006;94:101-127. 
[40] van der Hoven I. Power spectrum of horizontal wind speed in the frequency range from 0.0007-900 cycles per hour. J Meteo. 1957;14:160-164.

[41] Sumner GN. The nature and development of rainstorms in Coastal East Africa. J Climatol. 1981;1:131-152.

[42] Blocken B, Carmeliet J. On the errors associated with the use of hourly data in wind-driven rain calculations on building facades. Atmos Environ. 2007;41:2335-2343.

[43] Blocken B, Carmeliet J. Guidelines for the required time resolution of meteorological input data for wind-driven rain calculations on buildings. J Wind Eng Ind Aerodyn. 2008;96:621-639.

[44] Dunkerley D. Identifying individual rain events from pluviograph records: a review with analysis of data from an Australian dryland site. Hydrol Process. 2008;22:5024-5036.

[45] Blocken B, Roels S, Carmeliet J. A combined CFD-HAM approach for wind-driven rain on building facades. J Wind Eng Ind Aerodyn. 2007;95:585-607.

[46] ISO 2009. Hygrothermal performance of buildings - calculation and presentation of climatic data - Part 3:

calculation of a driving rain index for vertical surfaces from hourly wind and rain data. ISO 15927-3:2009 International Organization for Standardization.

[47] ASHRAE 2009. ASHRAE Standard 160 - Criteria for moisture control design analysis in buildings. AHSRAE, Atlanta, USA.

[48] Janssen $\mathrm{H}$, Blocken B, Carmeliet J. Conservative modelling of the moisture and heat transfer in building components under atmospheric excitation. Int J Heat Mass Tran. 2007;50:1128-1140.

[49] Janssen H, Blocken B, Roels S, Carmeliet J. Wind-driven rain as a boundary condition for HAM simulations: Analysis of simplified modelling approaches. Build Environ. 2007;42:1555-1567. 


\section{FIGURES}

a)

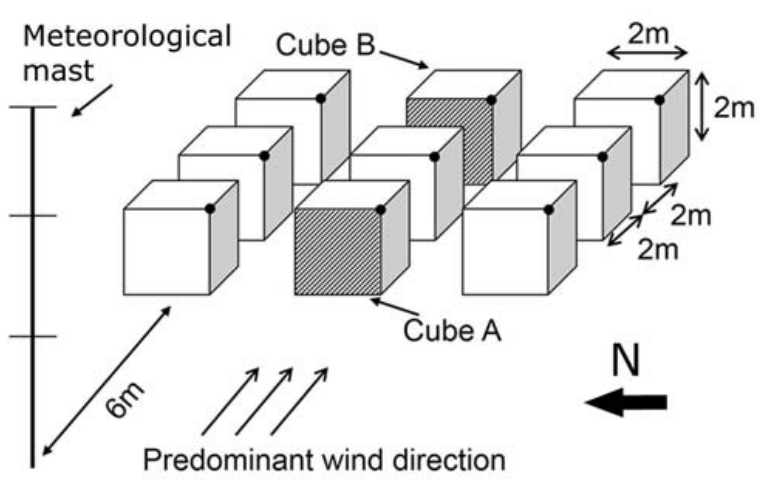

b)

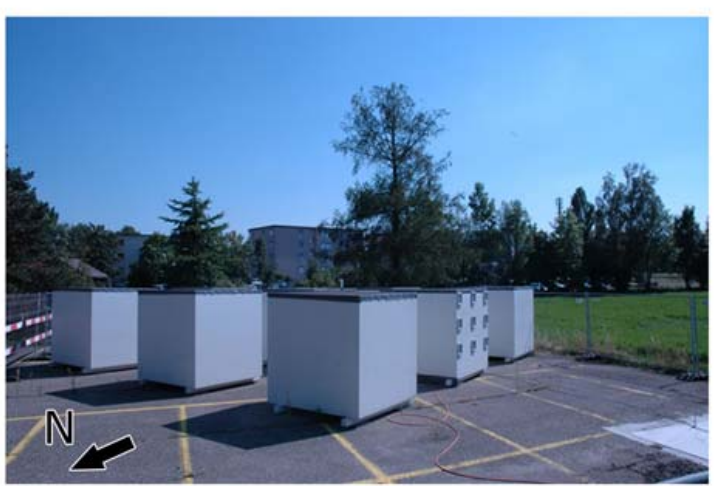

c)

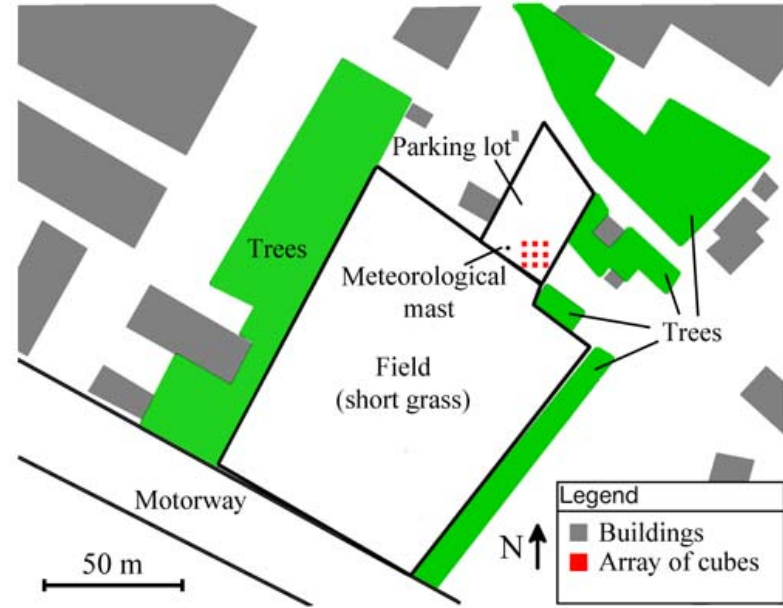

Fig. 1. a) Geometry of regular array of cubic building models for field measurements. The WDR measurements are conducted on the grey facades. b) View of the measurement site from northwest. c) Plan of the experimental site with the array of cubes and its surroundings.

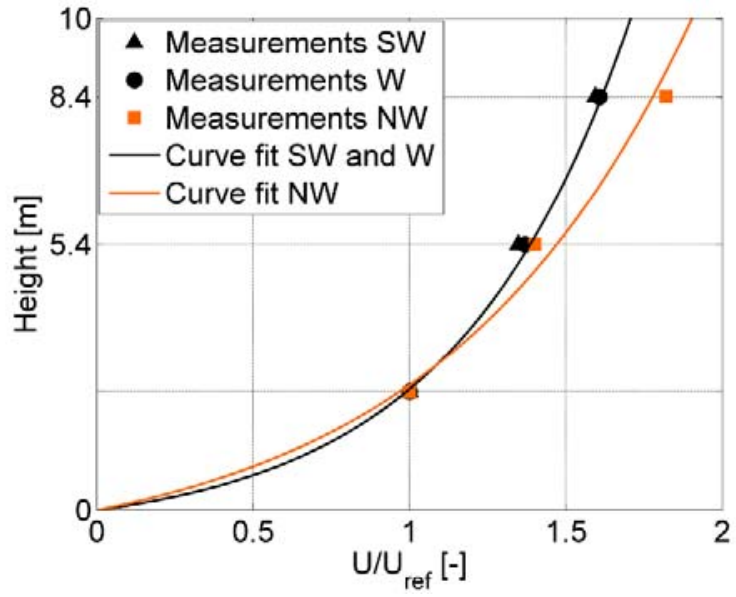

Fig. 2. Measurements and a log-law fit for the scaled approach flow wind speed profiles for wind direction from southwest, west and northwest. 


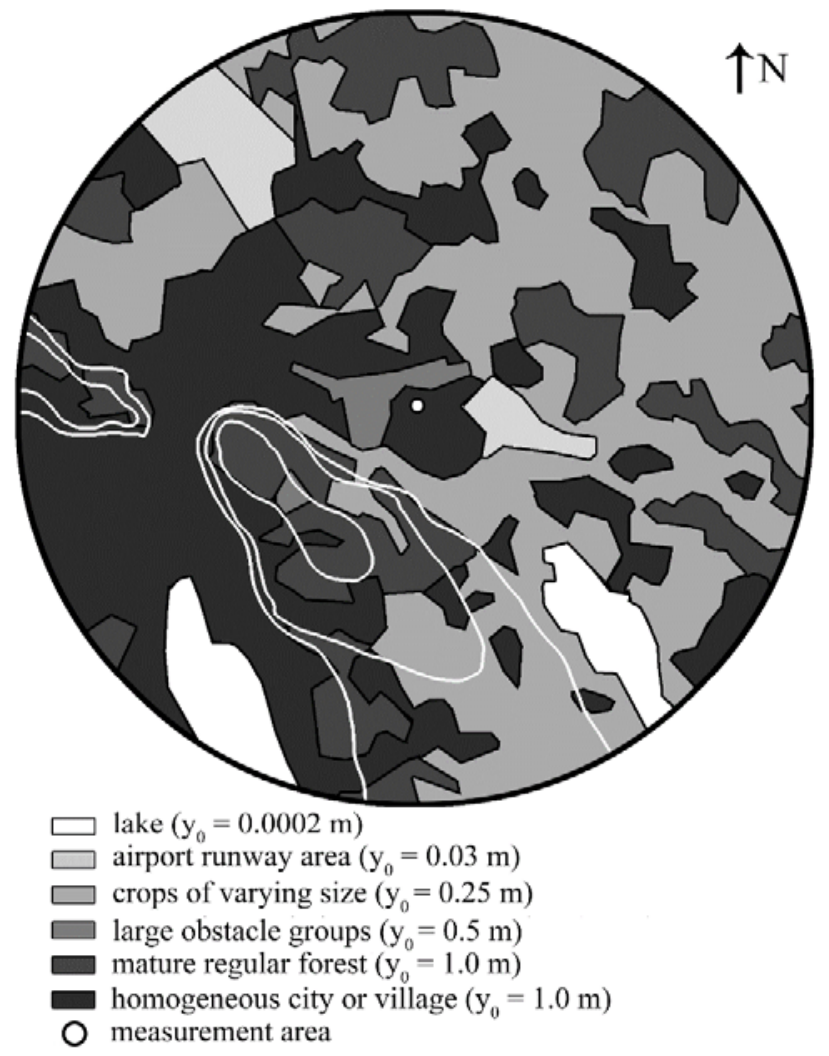

Fig. 3. Aerodynamic roughness length of the surroundings of the measurement site within a radius of 10 $\mathrm{km}$ according to the Davenport-Wieringa roughness classification [32]. White contour lines show the locations of two hills that are 150-250 m higher than their surroundings.

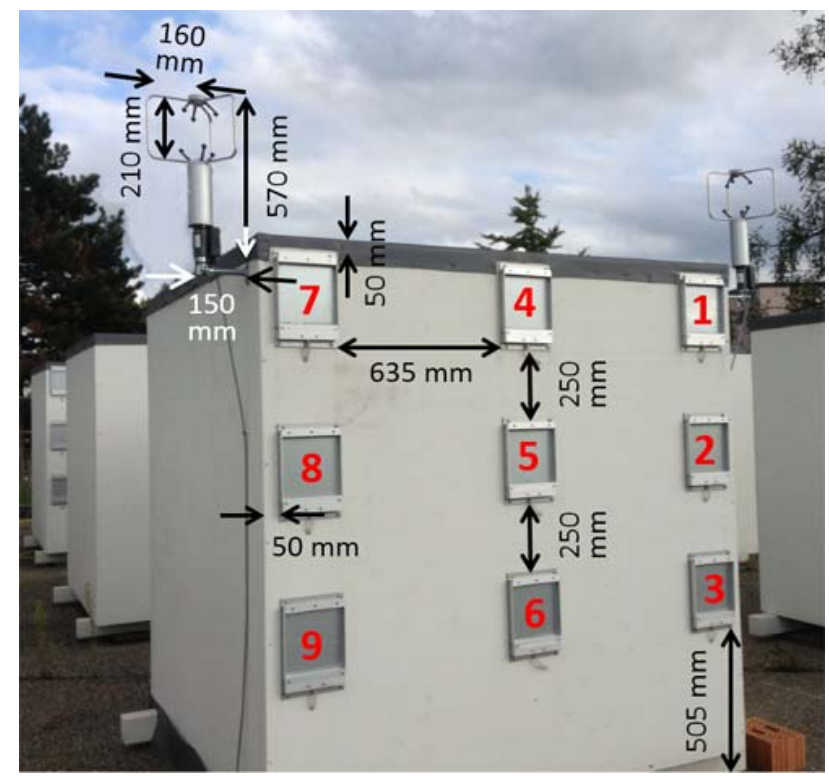

Fig. 4. Positions of two ultrasonic anemometers and of wind-driven rain gauges on cube A. 


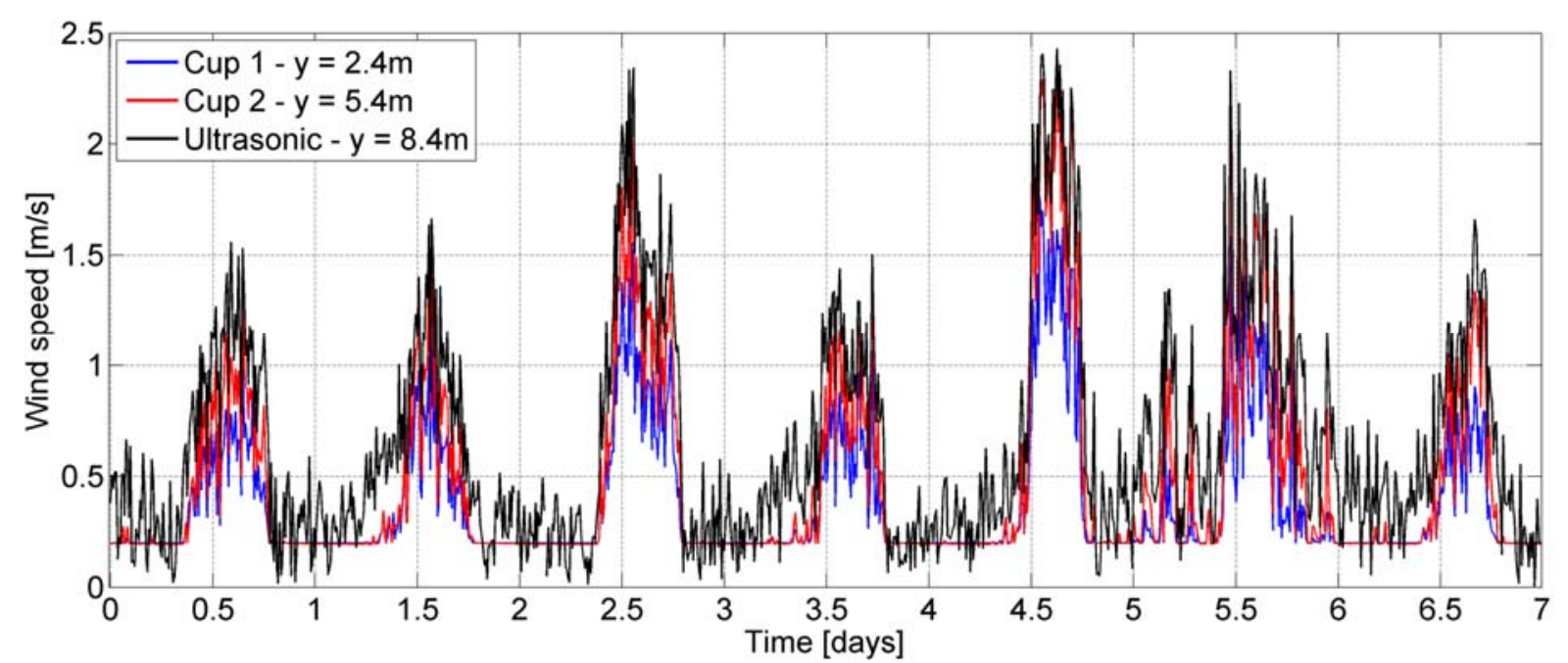

Fig. 5. Wind speed measurement data from all 5 anemometers using 10-min averaged values.

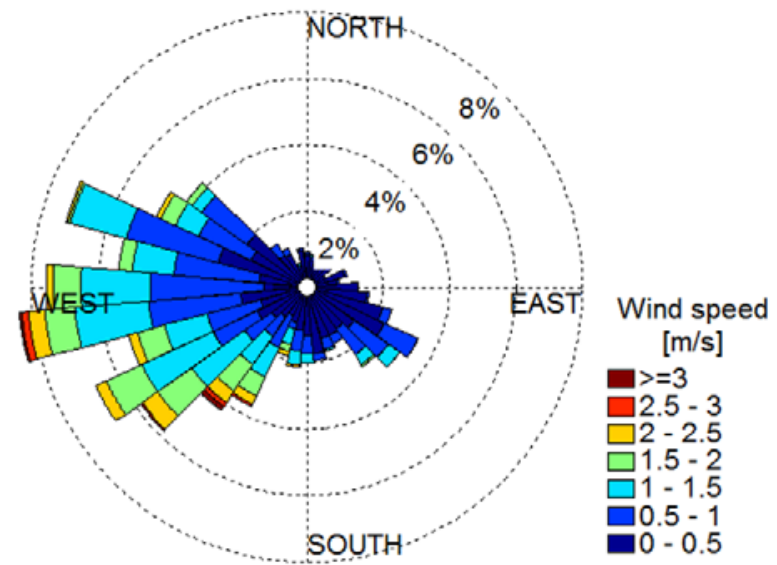

Fig. 6. Wind rose using 10-min averaged wind speed values at $2.4 \mathrm{~m}$ height between May 2013 and October 2013 during rain only. 
a)

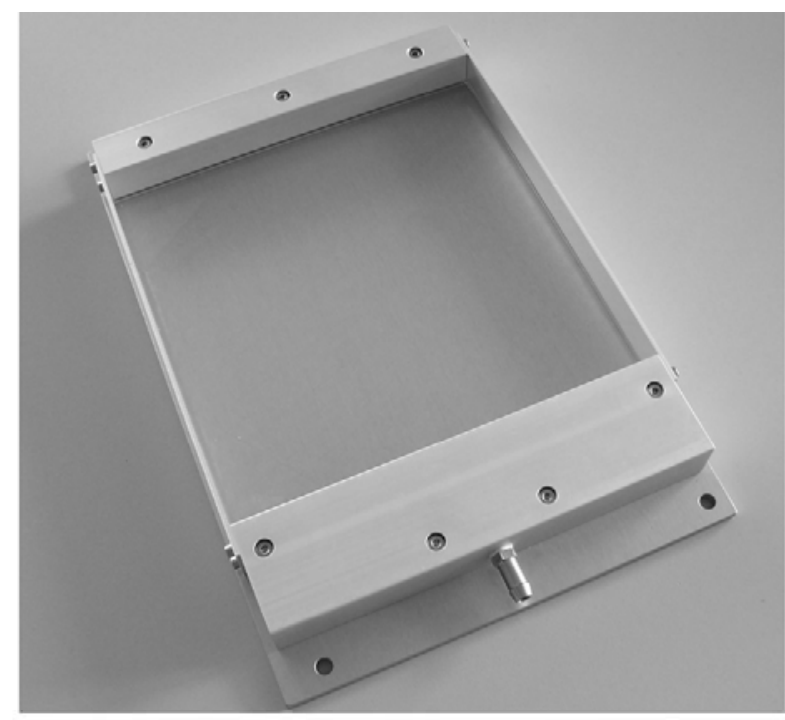

b)

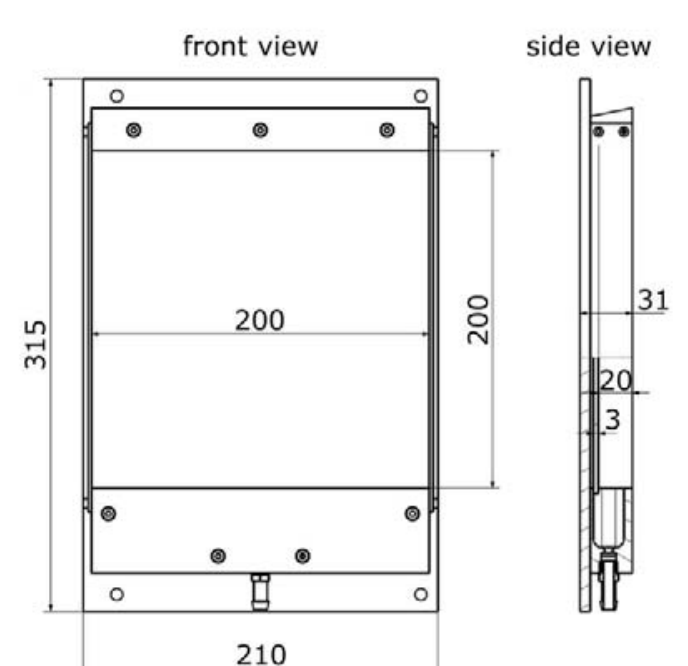

c)

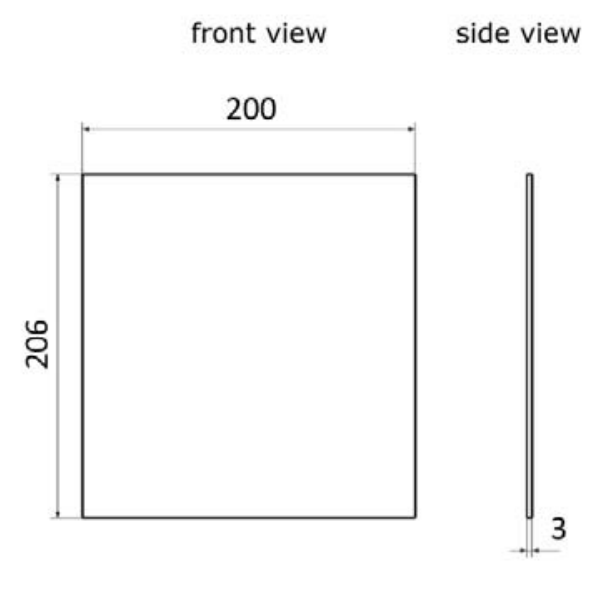

Fig. 7. a) View of the wind-driven rain gauge collector. b) Dimensions (in $\mathrm{mm}$ ) of the wind-driven rain gauge collector from the front and side. c) Dimensions (in $\mathrm{mm}$ ) of the glass surface. 


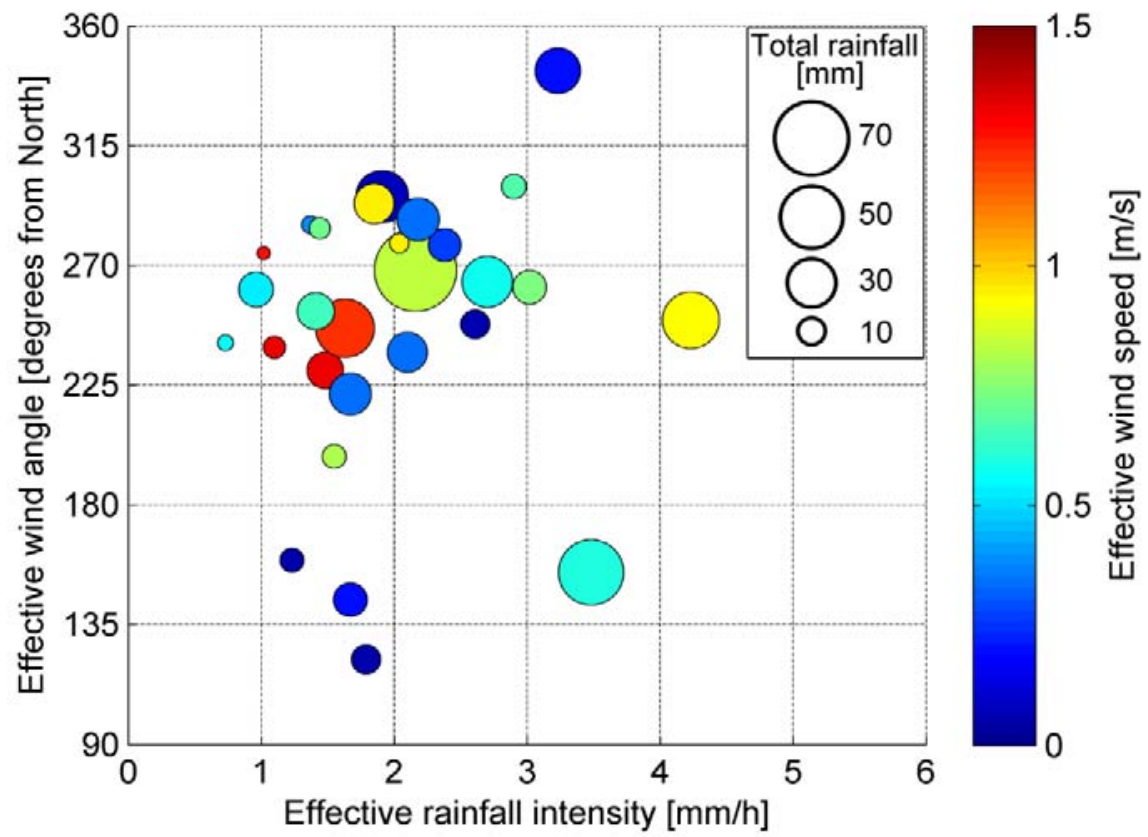

Fig. 8. Distribution of rain events in terms of their effective rainfall intensity, effective wind direction and effective wind speed values at $2.4 \mathrm{~m}$ height. The sizes of the circles are in proportion to the rainfall amount during the rain event. 
a)

Rain event 1: May 30 - June 1, 2013

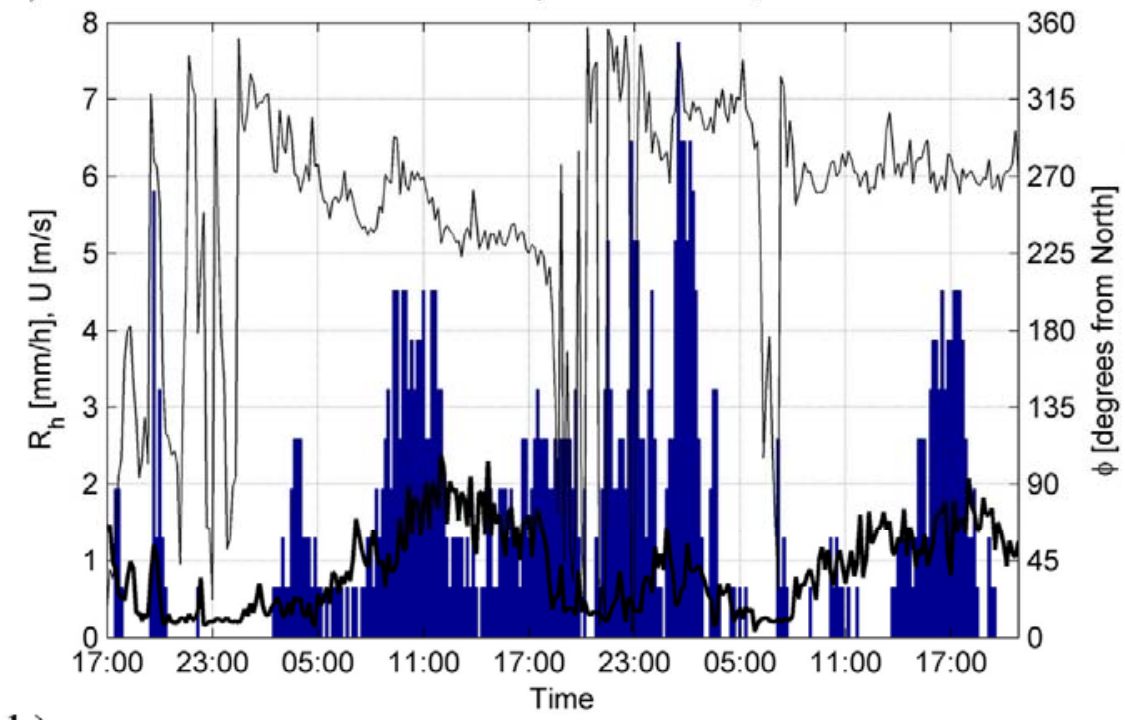

b)

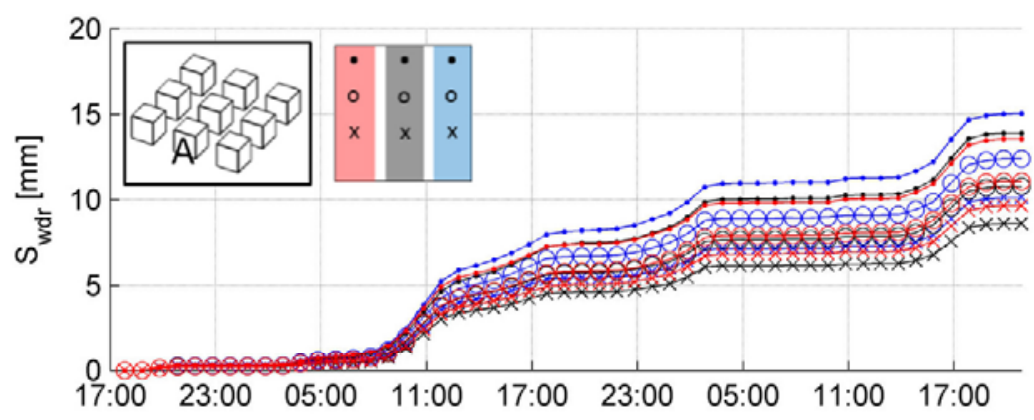

Cube A

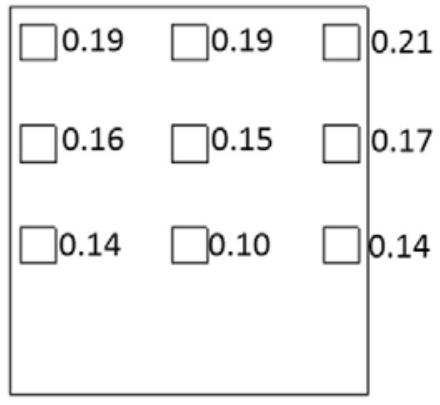

c)

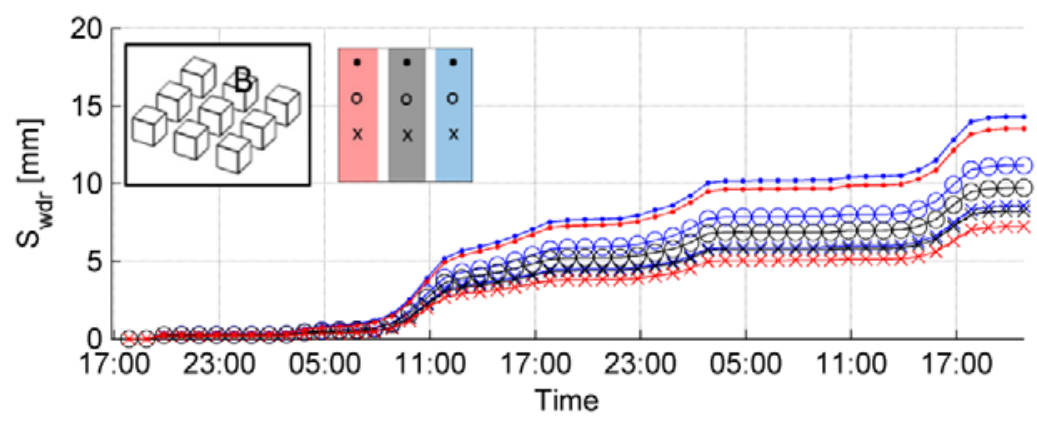

Cube B

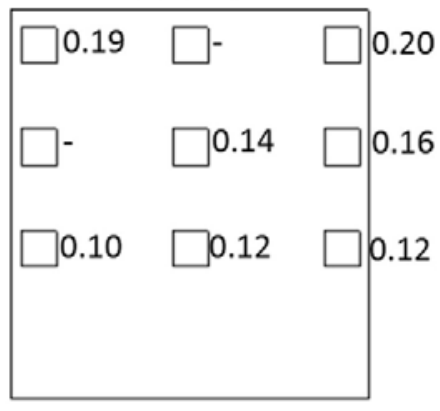

Fig. 9. a) 10-minute meteorological data for the rain event on May 30 - June 1, 2013. Wind speed is taken at $2.4 \mathrm{~m}$ height. b-c) Cumulative WDR amount measured by WDR gauges during the rain event (left) and the catch ratio values at the end of the rain event (right) on cubes A and B. 
a)

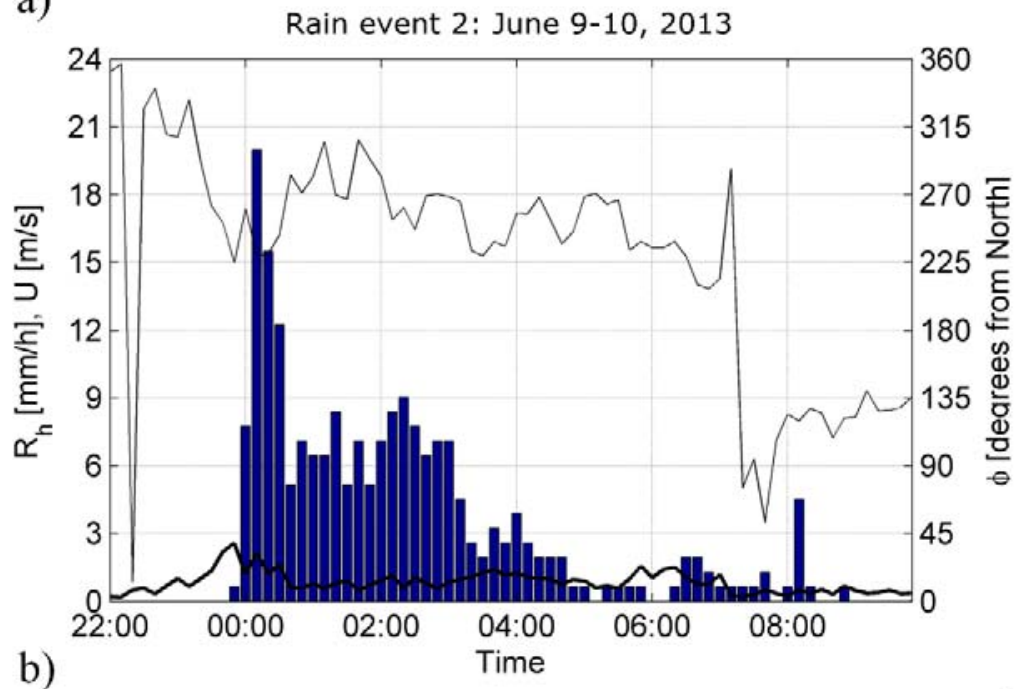

b)

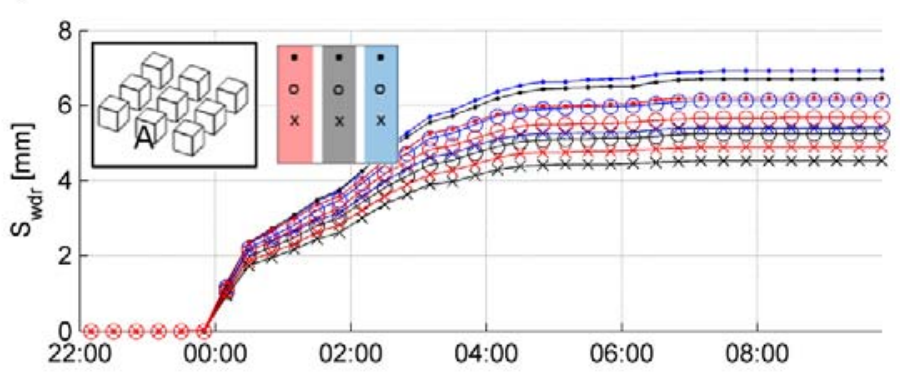

c)

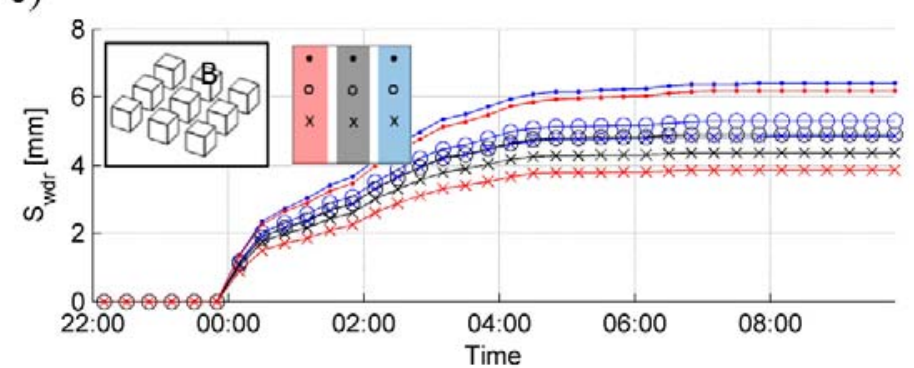

Rainfall intensity, $R_{h}$

Wind speed, $U$

Wind direction, $\varphi$

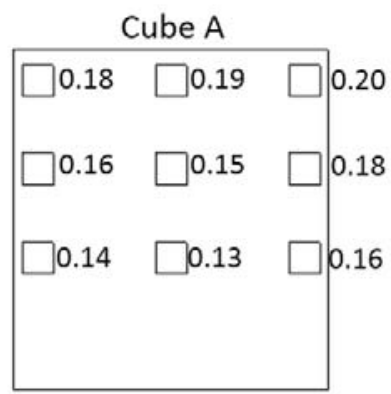

Cube B

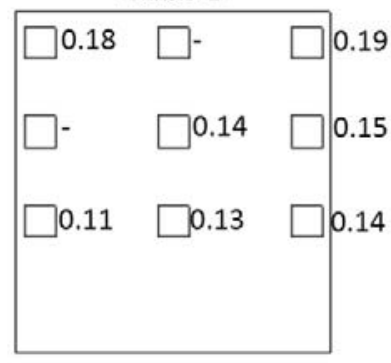

Fig. 10. a) 10-minute meteorological data for the rain event on June 9-10, 2013. Wind speed is taken at 2.4 $\mathrm{m}$ height. b-c) Cumulative WDR amount measured by WDR gauges during the rain event (left) and the catch ratio values at the end of the rain event (right) on cubes A and B. 
a)

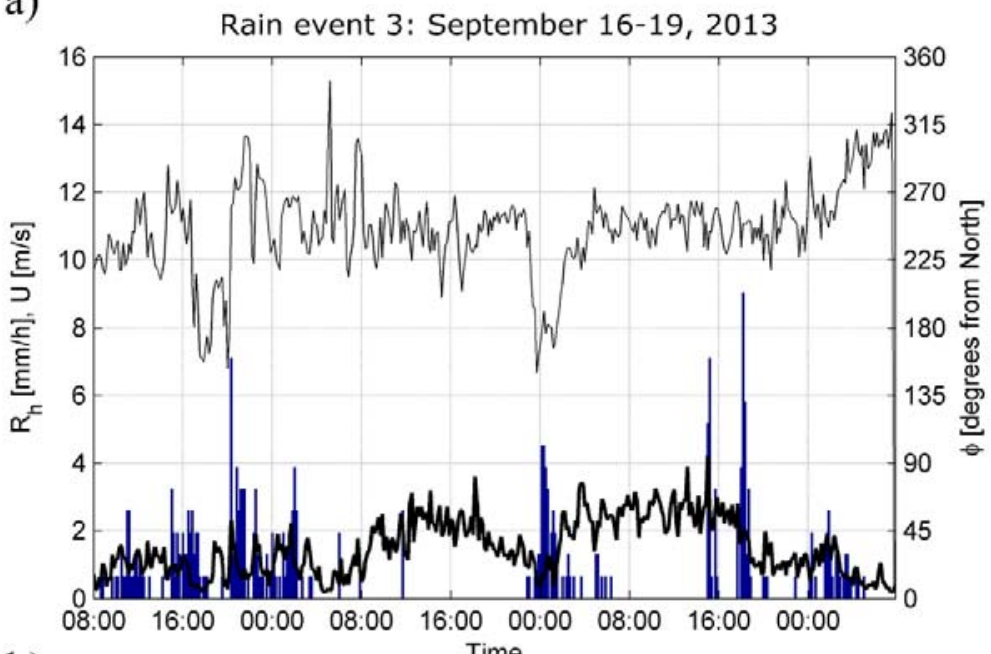

b)

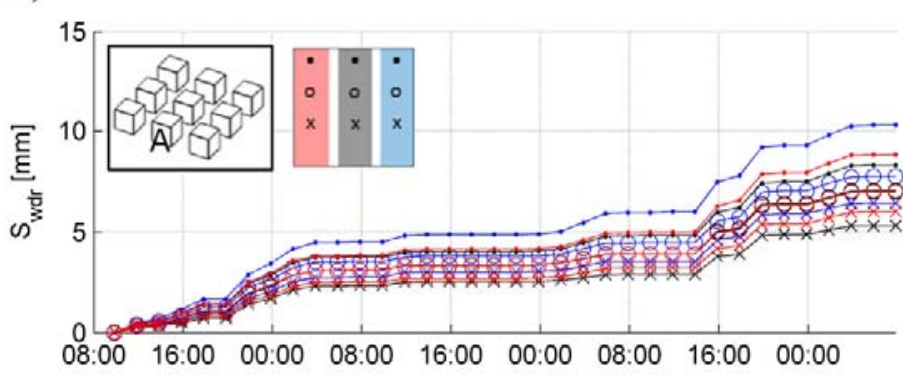

Cube A

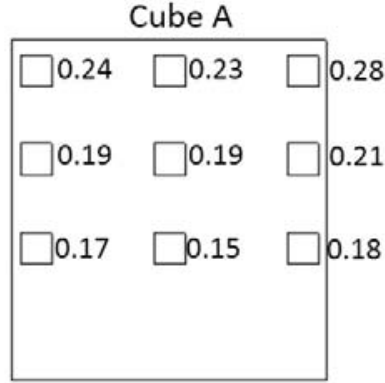

Cube $B$

c)
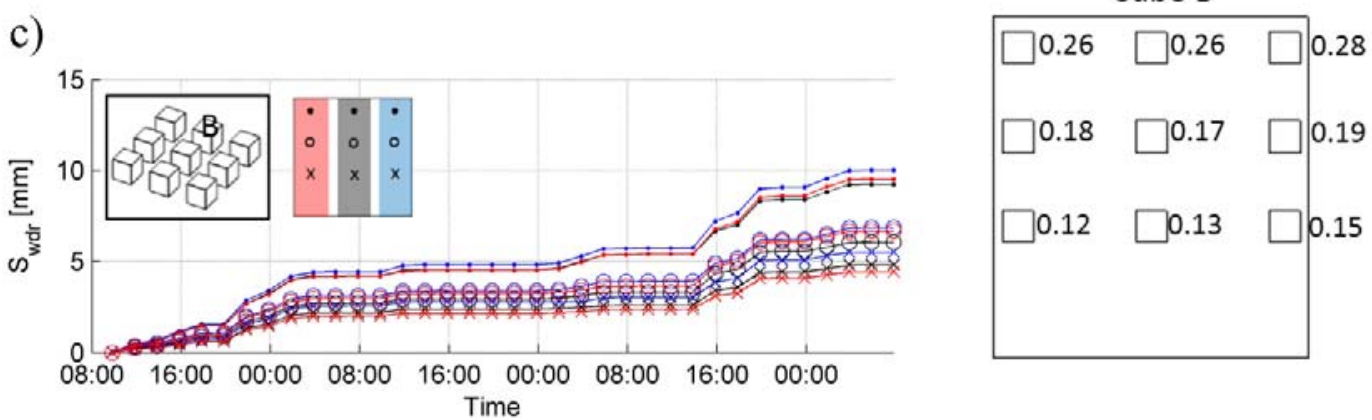

Fig. 11. a) 10-minute meteorological data for the rain event on September 16-19, 2013. Wind speed is taken at $2.4 \mathrm{~m}$ height. $\mathrm{b}$-c) Cumulative WDR amount measured by WDR gauges during the rain event (left) and the catch ratio values at the end of the rain event (right) on cubes A and B. 

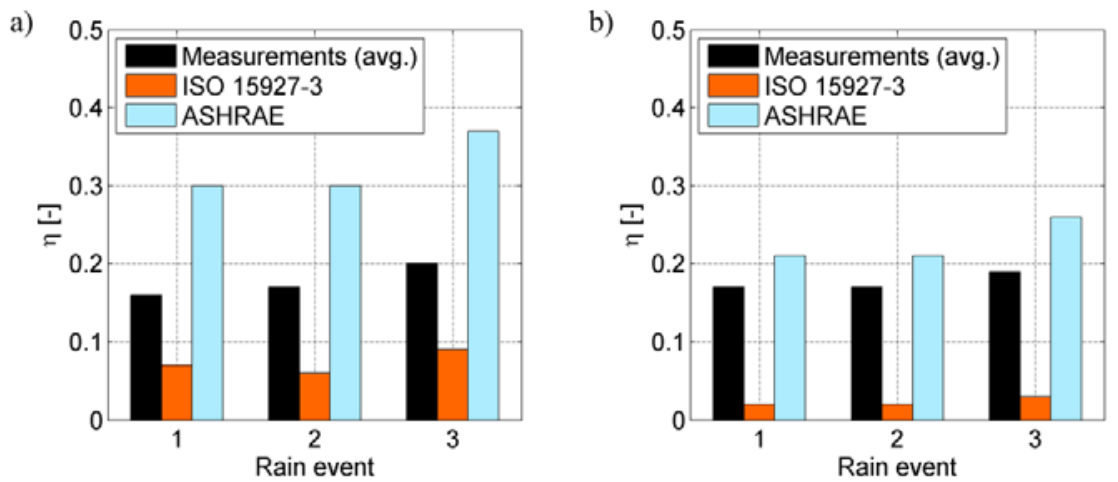

Fig. 12. Catch ratios estimated with the semi-empirical models on the test facades of cubes a) A and b) B in comparison to measurements (averaged over facade).

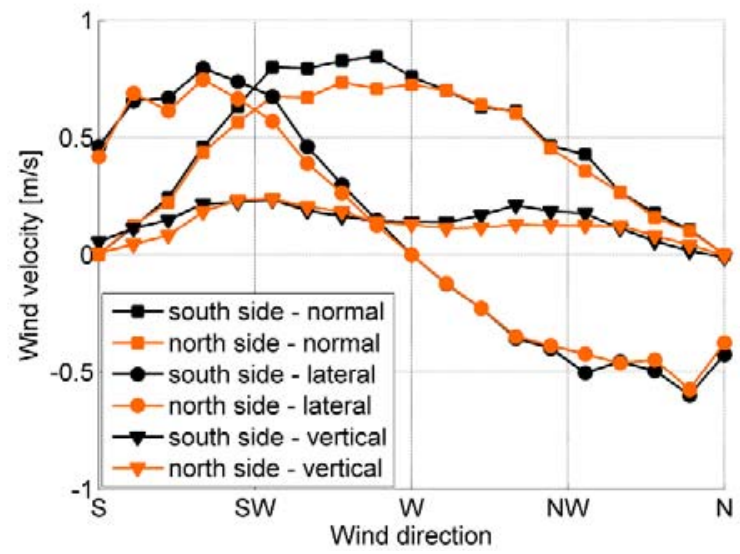

Fig. 13. The average values of wind velocity components measured between September 20th, 2013 and October 28th, 2013 by the ultrasonic anemometers installed on cube A. 


\section{TABLES}

Table 1. Cube A - calibration information for WDR gauges.

\begin{tabular}{llllllllll}
\hline $\begin{array}{l}\text { WDR } \\
\text { gauge }\end{array}$ & A1 & A2 & A3 & A4 & A5 & A6 & A7 & A8 & A9 \\
\hline $\begin{array}{l}\text { Bucket } \\
\text { volume }\end{array}$ & 0.956 & 1.128 & 1.018 & 0.955 & 0.969 & 0.961 & 0.912 & 1.069 & 1.128 \\
$\begin{array}{l}\text { [ml] } \\
\begin{array}{l}\text { Resolution } \\
{[\mathrm{mm} / \text { tip] }}\end{array}\end{array}$ & 0.024 & 0.028 & 0.025 & 0.024 & 0.024 & 0.024 & 0.023 & 0.027 & 0.028 \\
\hline
\end{tabular}

Table 2. Cube B - calibration information for WDR gauges.

\begin{tabular}{llllllllll}
\hline $\begin{array}{l}\text { WDR } \\
\text { gauge }\end{array}$ & B1 & B2 & B3 & B4 & B5 & B6 & B7 & B8 & B9 \\
\hline $\begin{array}{l}\text { Bucket } \\
\text { volume }\end{array}$ & 0.976 & 0.967 & 1.133 & 1.028 & 1.016 & 1.090 & 1.013 & 1.052 & 0.934 \\
$\begin{array}{l}{[\mathrm{ml}]} \\
\begin{array}{l}\text { Resolution } \\
{[\mathrm{mm} / \text { tip] }}\end{array}\end{array}$ & 0.024 & 0.024 & 0.028 & 0.026 & 0.025 & 0.027 & 0.025 & 0.026 & 0.023 \\
\hline
\end{tabular}

Table 3. Error estimates for the wind-driven rain measurements for the rain event on May 30 - June 1, 2013.

\begin{tabular}{cccccccccccc}
\hline $\begin{array}{l}\text { WDR } \\
\text { gauge }\end{array}$ & $\begin{array}{c}\text { Number } \\
\text { of tips }\end{array}$ & $\begin{array}{l}\mathrm{S}_{\mathrm{wdr}} \\
{[\mathrm{mm}]}\end{array}$ & $\begin{array}{l}\mathrm{E}_{\mathrm{AW}} \\
{[\mathrm{mm}]}\end{array}$ & $\begin{array}{l}\mathrm{E}_{\mathrm{RW}} \\
{[\mathrm{mm}]}\end{array}$ & $\begin{array}{c}\mathrm{E}_{\mathrm{TOT}} \\
(\%)\end{array}$ & $\begin{array}{c}\text { WDR } \\
\text { gauge }\end{array}$ & $\begin{array}{c}\text { Number } \\
\text { of tips }\end{array}$ & $\begin{array}{l}\mathrm{S}_{\mathrm{wdr}} \\
{[\mathrm{mm}]}\end{array}$ & $\begin{array}{l}\mathrm{E}_{\mathrm{AW}} \\
{[\mathrm{mm}]}\end{array}$ & $\begin{array}{l}\mathrm{E}_{\mathrm{RW}} \\
{[\mathrm{mm}]}\end{array}$ & $\begin{array}{l}\mathrm{E}_{\mathrm{TOT}} \\
(\%)\end{array}$ \\
\hline $\mathrm{A} 1$ & 630 & 15.06 & 0.640 & 0.120 & 5.0 & $\mathrm{~B} 1$ & 587 & 14.32 & 0.640 & 0.120 & 5.3 \\
$\mathrm{~A} 2$ & 440 & 12.41 & 0.640 & 0.140 & 6.3 & $\mathrm{~B} 2$ & 461 & 11.14 & 0.640 & 0.120 & 6.8 \\
$\mathrm{~A} 3$ & 398 & 10.13 & 0.640 & 0.125 & 7.6 & $\mathrm{~B} 3$ & 301 & 8.53 & 0.640 & 0.140 & 9.1 \\
$\mathrm{~A} 4$ & 583 & 13.92 & 0.640 & 0.120 & 5.5 & $\mathrm{~B} 4$ & - & - & 0.640 & 0.130 & - \\
$\mathrm{A} 5$ & 446 & 10.80 & 0.640 & 0.120 & 7.0 & $\mathrm{~B} 5$ & 382 & 9.70 & 0.640 & 0.125 & 7.9 \\
$\mathrm{~A} 6$ & 358 & 8.60 & 0.640 & 0.120 & 8.8 & $\mathrm{~B} 6$ & 301 & 8.20 & 0.640 & 0.135 & 9.5 \\
$\mathrm{~A} 7$ & 595 & 13.57 & 0.640 & 0.115 & 5.6 & $\mathrm{~B} 7$ & 535 & 13.55 & 0.640 & 0.125 & 5.6 \\
$\mathrm{~A} 8$ & 415 & 11.09 & 0.640 & 0.135 & 7.0 & $\mathrm{~B} 8$ & - & - & 0.640 & 0.130 & - \\
$\mathrm{A} 9$ & 342 & 9.64 & 0.640 & 0.140 & 8.1 & $\mathrm{~B} 9$ & 309 & 7.22 & 0.640 & 0.115 & 10.5 \\
\hline
\end{tabular}

Table 4. Error estimates for the wind-driven rain measurements for the rain event on June 9-10, 2013.

\begin{tabular}{cccccccccccc}
\hline $\begin{array}{c}\text { WDR } \\
\text { gauge }\end{array}$ & $\begin{array}{c}\text { Number } \\
\text { of tips }\end{array}$ & $\begin{array}{c}\mathrm{S}_{\mathrm{wdr}} \\
{[\mathrm{mm}]}\end{array}$ & $\begin{array}{l}\mathrm{E}_{\mathrm{AW}} \\
{[\mathrm{mm}]}\end{array}$ & $\begin{array}{l}\mathrm{E}_{\mathrm{RW}} \\
{[\mathrm{mm}]}\end{array}$ & $\begin{array}{c}\mathrm{E}_{\mathrm{TOT}} \\
(\%)\end{array}$ & $\begin{array}{c}\text { WDR } \\
\text { gauge }\end{array}$ & $\begin{array}{c}\text { Number } \\
\text { of tips }\end{array}$ & $\begin{array}{l}\mathrm{S}_{\mathrm{wdr}} \\
{[\mathrm{mm}]}\end{array}$ & $\begin{array}{l}\mathrm{E}_{\mathrm{AW}} \\
{[\mathrm{mm}]}\end{array}$ & $\begin{array}{l}\mathrm{E}_{\mathrm{RW}} \\
{[\mathrm{mm}]}\end{array}$ & $\begin{array}{c}\mathrm{E}_{\mathrm{TOT}} \\
(\%)\end{array}$ \\
\hline $\mathrm{A} 1$ & 289 & 6.91 & 0.128 & 0.024 & 2.2 & $\mathrm{~B} 1$ & 262 & 6.39 & 0.128 & 0.024 & 2.4 \\
$\mathrm{~A} 2$ & 217 & 6.12 & 0.128 & 0.028 & 2.5 & $\mathrm{~B} 2$ & 219 & 5.29 & 0.128 & 0.024 & 2.9 \\
$\mathrm{~A} 3$ & 212 & 5.40 & 0.128 & 0.025 & 2.8 & $\mathrm{~B} 3$ & 171 & 4.84 & 0.128 & 0.028 & 3.2 \\
$\mathrm{~A} 4$ & 281 & 6.71 & 0.128 & 0.024 & 2.3 & $\mathrm{~B} 4$ & - & - & 0.128 & 0.026 & - \\
$\mathrm{A} 5$ & 216 & 5.23 & 0.128 & 0.024 & 2.9 & $\mathrm{~B} 5$ & 193 & 4.90 & 0.128 & 0.025 & 3.1 \\
$\mathrm{~A} 6$ & 188 & 4.52 & 0.128 & 0.024 & 3.4 & $\mathrm{~B} 6$ & 160 & 4.36 & 0.128 & 0.027 & 3.6 \\
$\mathrm{~A} 7$ & 272 & 6.20 & 0.128 & 0.023 & 2.4 & $\mathrm{~B} 7$ & 244 & 6.17 & 0.128 & 0.025 & 2.5 \\
$\mathrm{~A} 8$ & 212 & 5.67 & 0.128 & 0.027 & 2.7 & $\mathrm{~B} 8$ & - & - & 0.128 & 0.026 & - \\
$\mathrm{A} 9$ & 173 & 4.88 & 0.128 & 0.028 & 3.2 & $\mathrm{~B} 9$ & 165 & 3.85 & 0.128 & 0.023 & 3.9 \\
\hline
\end{tabular}


Table 5. Error estimates for the wind-driven rain measurements for the rain event on September 16-19, 2013.

\begin{tabular}{cccccccccccc}
\hline $\begin{array}{c}\text { WDR } \\
\text { gauge }\end{array}$ & $\begin{array}{l}\text { Number } \\
\text { of tips }\end{array}$ & $\begin{array}{c}\mathrm{S}_{\mathrm{wdr}} \\
{[\mathrm{mm}]}\end{array}$ & $\begin{array}{l}\mathrm{E}_{\mathrm{AW}} \\
{[\mathrm{mm}]}\end{array}$ & $\begin{array}{l}\mathrm{E}_{\mathrm{RW}} \\
{[\mathrm{mm}]}\end{array}$ & $\begin{array}{l}\mathrm{E}_{\mathrm{TOT}} \\
(\%)\end{array}$ & $\begin{array}{c}\text { WDR } \\
\text { gauge }\end{array}$ & $\begin{array}{l}\text { Number } \\
\text { of tips }\end{array}$ & $\begin{array}{l}\mathrm{S}_{\mathrm{wdr}} \\
{[\mathrm{mm}]}\end{array}$ & $\begin{array}{l}\mathrm{E}_{\mathrm{AW}} \\
{[\mathrm{mm}]}\end{array}$ & $\begin{array}{l}\mathrm{E}_{\mathrm{RW}} \\
{[\mathrm{mm}]}\end{array}$ & $\begin{array}{l}\mathrm{E}_{\mathrm{TOT}} \\
(\%)\end{array}$ \\
\hline $\mathrm{A} 1$ & 431 & 10.30 & 1.280 & 0.240 & 14.8 & $\mathrm{~B} 1$ & 410 & 10.00 & 1.280 & 0.240 & 15.2 \\
$\mathrm{~A} 2$ & 275 & 7.76 & 1.280 & 0.280 & 20.1 & $\mathrm{~B} 2$ & 284 & 6.87 & 1.280 & 0.240 & 22.1 \\
$\mathrm{~A} 3$ & 253 & 6.44 & 1.280 & 0.250 & 23.8 & $\mathrm{~B} 3$ & 194 & 5.50 & 1.280 & 0.280 & 28.4 \\
$\mathrm{~A} 4$ & 348 & 8.31 & 1.280 & 0.240 & 18.3 & $\mathrm{~B} 4$ & 360 & 9.25 & 1.280 & 0.260 & 16.6 \\
$\mathrm{~A} 5$ & 291 & 7.05 & 1.280 & 0.240 & 21.6 & $\mathrm{~B} 5$ & 239 & 6.07 & 1.280 & 0.250 & 25.2 \\
$\mathrm{~A} 6$ & 221 & 5.31 & 1.280 & 0.240 & 28.6 & $\mathrm{~B} 6$ & 176 & 4.80 & 1.280 & 0.270 & 32.3 \\
$\mathrm{~A} 7$ & 387 & 8.82 & 1.280 & 0.230 & 17.1 & $\mathrm{~B} 7$ & 376 & 9.52 & 1.280 & 0.250 & 16.1 \\
$\mathrm{~A} 8$ & 262 & 7.00 & 1.280 & 0.270 & 22.1 & $\mathrm{~B} 8$ & 254 & 6.68 & 1.280 & 0.260 & 23.1 \\
$\mathrm{~A} 9$ & 213 & 6.01 & 1.280 & 0.280 & 26.0 & $\mathrm{~B} 9$ & 189 & 4.41 & 1.280 & 0.230 & 34.2 \\
\hline
\end{tabular}

Table 6. Parameters for semi-empirical WDR models

\begin{tabular}{lll}
\hline Model & Parameters & \\
\hline ISO 15927-3 [46] & $C_{R}=0.83$ & \\
$C_{T}=1.00$ & \\
$W=0.40 \quad$ (average value for a two-storey building with flat roof) & \\
$O=0.70$, & cube A (distance: $60-80 \mathrm{~m})$ \\
0.20, & cube B $($ distance $<4 \mathrm{~m})$ \\
& & \\
& $F_{E}=1.00$, & cube A (medium exposure, height $<10 \mathrm{~m})$ \\
0.70, & cube B (sheltered exposure, height $<10 \mathrm{~m})$ \\
& $F_{D}=1.00 \quad$ (flat roof building) \\
\hline
\end{tabular}

